\title{
Chapter 11 \\ Trade Linkages to Traditional \\ and Non-Traditional Security: Lessons \\ and Prospects
}

\author{
Vinod K. Aggarwal and Kristi Govella
}

\subsection{Introduction}

With ongoing problems in concluding the Doha Round of the World Trade Organization (WTO), countries have pursued a variety of alternative trade arrangements to increase market access. In particular, we have seen a dramatic increase in efforts in the Asia-Pacific to conclude transregional, regional, and bilateral free trade agreements (FTAs). Yet belying their apparent focus on technical matters of tariffs and other trade barriers, such agreements have become increasingly politicized. Driven both by state interests and the growing activism of domestic actors, many countries have sought to promote both traditional and nontraditional security goals through explicit and implicit linkages. Analysts have recognized this phenomenon, arguing that US trade agreements have become increasingly "securitized" (Higgott 2004). Others have focused on the degree to which such accords might lead to better labor or environmental standards. ${ }^{1}$ Yet to this point, we do not have a theoretically informed, comprehensive analysis of trade linkages that encompasses both trade and non-trade issues, or one that focuses broadly on the Asia Pacific. This book attempts to fill those gaps.

This chapter's goal is to extract lessons from the empirical analysis of linkages across the broad spectrum of trade arrangements ranging from the WTO to bilateral FTAs. In doing so, we hope to shed light on how our initial theoretical and conceptual perspective on the driving forces of trade linkages and their impact

1 See among others Hafner-Burton (2005) and Vogel (1995).

V. K. Aggarwal $(\bowtie) \cdot$ K. Govella

University of California, Berkeley, USA

e-mail: vinod@berkeley.edu

K. Govella

e-mail:kgovella@berkeley.edu 
fares in light of this analysis. To that end, Sect. 11.2 briefly reviews the theoretical arguments of Chap. 1, focusing on the analytical framework that provided the underlying analytical lens for the case study writers. Section 11.3 provides an analytical summary of the empirical findings on linkage efforts, focusing on the linkage patterns that we can discern among the variety of trade accords discussed in the case studies. Section 11.4 attempts to outline some general findings from the case analyses along the lines of our variables of interest and concludes with our expectations about future efforts to engage in linkages in the Asia Pacific.

\subsection{The Conceptual and Theoretical Approach: A Summary}

To describe and explain how actors attempt to engage in both traditional and nontraditional security linkages, Chap. 1 introduced our approach, which consists of three parts.

The first element, our conceptual approach, points to the direct causal drivers of linkages to trade, which include traditional security, non-traditional security, and broader economic considerations (see Fig. 1.1). Once trade agreements have been concluded, they may impact traditional and nontraditional security along two paths: one is the direct impact of the agreement (e.g., directives to improve worker's rights in a target country), and the other is the indirect impact (e.g., through more rapid trade and economic growth that enhances or diminishes protection of the environment). This general conceptualization provides a frame for the chapter authors to examine issue linkages. In the empirical analyses, depending on the length of time that various agreements have been in operation or are currently being negotiated, different writers emphasize different aspects of this process, viz. the domestic agenda-setting process, international negotiations, and the impact of accords on actual state behavior.

The second part of our analysis consists of an effort to build on previous work to specify the variety of trade agreements and to systematically characterize them on three central dimensions. The dimensions we proposed to consider and which the case study authors have focused on include the number of participants involved in an agreement, geographical scope, and underlying organizational structure. ${ }^{2}$ Our goal here is to provide a conceptual analysis of accords with an eye to better understanding whether the process of linkage formation and the impact of trade agreements on traditional and non-traditional security are conditioned by the types of agreements being negotiated. Moreover, depending on linkage goals, the dimensions can also serve not only as intervening factors for pre-existing arrangements, but also as goals themselves for negotiators: e.g., concluding more binding accords with dispute settlement to enforce outcomes.

2 See Aggarwal (2001) and Pekkanen (forthcoming). 
The third element in our effort to explain the use of trade linkages focuses specifically on two key processes. The first concerns the domestic political economy of linkage formation; the second focuses on international negotiations. We suggest that one important aspect of linkage formation could be understood by considering linkages on the dimension of knowledge consensus, building on the work of Ernst Haas (Haas 1980). ${ }^{3}$ If linkages are based on power, we refer to these as tactical. If they are based on consensual knowledge, they are labeled substantive. Supplementing Haas's approach, we also considered two key aspects of linkages with respect to linkers and linkees (Aggarwal 1998). If both parties see the issues as substantively linked, then one has a genuine substantive linkage. If both recognize that the effort is a power play, then the linkage is tactical.

As we suggested, however, the most interesting dynamics in linkage politics are often more complicated. For example, in the domestic arena, when experts and other advocates agree that two issues are interconnected (e.g. the connection between trade and labor standards), even policymakers who do not believe that the two issues are substantively linked may still treat them together to mollify interest groups for political gain. Similarly, in an international context, the target country may deny that the linkage is substantive but still go along with the demands of the linker because of a perceived asymmetry of power. This type of linkage can be seen as "failed substantive linkage"-where failure refers to the basis of cooperation, not the ultimate outcome of agreeing to the policy pushed by the linker. This situation might be rectified. Both domestically and internationally, advocates for such linkages may attempt to sway their target audiences through provision of information to convince them of the substantive validity of the issue linkage. Thus, over time, with changed causal understanding, we may see a move to a "successful" substantive linkage, which also may prove to be more stable as a basis for cooperation. Otherwise, power shifts in the direction of the reluctant linkee are likely to undermine any linkage effort over the longer run as the linkee moves to position where resistance is now possible.

The last case we consider refers to a situation where the linkee sees the issues as substantively linked-even though the linker never intended this. In such a case, which we refer to as a misperceived tactical linkage, the target decisionmakers may have experts or other interest groups who recognize that there really no substantive linkage and push the decisionmakers to resist the linkage with counterpower efforts. Although the linkee may go along with the linker's efforts for the wrong reason (belief that there is a substantive connection), this situation may prove unstable - as in the case of misperceived substantive linkages - in a different way. If and when the target comes to realize that the connection was tactical in nature, the bargaining connection will shift to a potentially unstable one that will only endure as long as the linker maintains its superior power.

A key aspect of the linkage process is the role of power. Here, we refer to the impact of the distribution of power, both international and domestic, on the

3 Also see Oye (1992). 
outcomes of tactical linkages. Whether domestically or internationally, the power distribution in these types of linkages, tied to the salience of the issues for both linkers and linkees, directly affects outcomes. At the domestic level, the success or failure of interest groups will be determined by the asymmetry of power and interests, factors that are themselves a function of state-society relationships. In many countries in Asia, in contrast to Western states, for example, the state itself may pursue a set of goals and domestically powerful states may be more prone to ignore pressure groups.

Internationally, power asymmetry will by definition be critical in the use of tactical linkages. But since states pursue a host of goals, both domestically and internationally, there is unlikely to be a one-to-one correspondence between asymmetry of overall power and outcomes. Instead, given domestic constraints and competing international objectives, the circumstances of pressure by linkers on linkees (and their counter response) must be explicitly analyzed, focusing both on positive and negative inducements.

We can summarize the three elements of our conceptual and theoretical analysis to examine the case study findings as follows. ${ }^{4}$ The first element concerns our broad general framework. On this score, we are interested in (1) exploring the extent to which we see the use of security, non-security, and broader economic linkages in the agreement being discussed; and (2) examining the evidence for direct effects of the agreement on traditional and non-traditional security issues. Our second element focused on types of agreements-in particular on their membership, geographical scope, and underlying organizational structure. Here, our central interest is to analyze the how differences on these three dimensions (or other aspects raised by authors) might influence the linkage process and subsequent impact of such linkages. Finally, we consider the bases for linkages themselves. First, do we see evidence of different types of linkages (substantive, tactical, failed) in the domestic process leading to different types of international agreements? And second, do we see evidence of power asymmetries domestically and internationally in negotiations in these respective spheres? With these elements in mind, we turn to our case studies.

\subsection{Findings from the Case Analyses}

As we suggested, one logical categorization of agreements is by the number of actors involved. Thus, we begin by considering linkage processes with the broadest level agreement, the GATT/WTO. Then, we examine minilateral accords including Asia Pacific Economic Cooperation (APEC), the Association of Southeast Asian Nations (ASEAN), the "ASEAN Plus X" groupings (e.g., ASEAN+1, ASEAN+3, and

\footnotetext{
${ }^{4}$ Naturally, depending on the type of agreement and the length it has been in operation, all cases may not directly address these questions.
} 
the East Asia Summit), and the Shanghai Cooperation Organization (SCO). Finally, we look at the bilateral FTAs initiated by Asian countries involving security and non-security linkages and the FTAs of the US and EU.

In brief summary, David Vogel's chapter on the GATT/WTO finds that linkages to non-trade issues have indeed been an important part of negotiations in this organization. The most significant ones are those related to security, followed by environmental ones, and the weakest being ties to labor. He finds that these linkages have had an influence at a variety of points, including membership criteria, the onset of new trade negotiations, WTO standing bodies, the policies of the WTO, and dispute panel rulings. Finally, we see considerable asymmetry in trade negotiations, with jostling among developed and developing countries and often within these groups themselves. Because of the lack of clear consensus on linkages among trade, security, and non-security issues, we see some degree of substantive linkages but a much greater use of tactical linkages along with some cases of failed substantive linkages.

With respect to security linkages, the GATT was deeply nested within the bipolar system, with the goal of promoting economic development to bolster the Western alliance. The security connection was evident in the US withdrawal of trade concessions to Czechoslovakia and Cuba when they became communist and successfully pressured to have the Chinese withdraw from the GATT. The US then changed it position and encouraged East and Central European countries to join the GATT, albeit as second-class citizens without full privileges. With respect to the WTO, as noted in the introduction to the book, after the 9/11 attacks, the US used this incident to press for conclusion of the Doha Round to "fight terrorism." Thus, as we have seen, traditional security considerations have been an important consideration with respect to the US and the GATT/WTO.

In terms of non-security linkages, as Vogel notes, the key stimulant to the politicization of the WTO with respect to the environment came with a dispute panel ruling with respect to the killing of dolphins in connection with the 1991 tuna fishing ruling, which forbade the US from banning tuna imports from three countries. The debate over whether environmental considerations should be substantively linked to trade now heated up, with activists criticizing this ruling. The outcome was the inclusion in the WTO preamble of a phrase on protecting allowing countries to invoke standards to protect the environment. Moreover, a systematic review of trade policy impact on the environment led to the creation of the Committee on Trade and Environment (CTE) in the WTO, which many developing countries rejected as a tactical linkage to impose green protectionism effort rather than a substantive one. Still, environmental issues were now firmly entrenched on the WTO agenda. But in terms of its rulings, various dispute settlement bodies tried to steer a narrow course and not explicitly link the various Multilateral Environmental Agreements (MEAs) directly to WTO rules. Thus, although there have been staff discussions to attempt to build consensus on linking trade and MEAs, in the absence of the conclusion of the Doha Round of the WTO, no new binding linkages have been explicitly created. 
With respect to labor, the biggest outstanding issue is how strongly the provisions of the GATT/WTO and the International Labor Organization's (ILO) provisions on the treatment of workers should be linked. Although there is an explicit linkage that allows countries to block imports of goods produced using prison labor, in general there has been tremendous opposition to tying labor rights to trade in the WTO, particularly by developing countries-despite US and EU efforts to do so. The vehement opposition of developing countries on this score comes from concern that pressure to improve labor standards, particularly those that would lead to higher wages, would undermine their global competitiveness.

Finally, human rights have been part of the WTO, through various clauses that allow members to refuse entry of products in cases of international human rights violations by countries, with a waiver of obligations permitted if three-quarters of the member states agree that there are violations. This has proved to be operational in the case of diamond trade, with over fifty members now applying for a waiver to allow them to ban imports from countries that have not agreed to the Kimberly Process certification process to deter the use of "conflict diamonds."

To sum up, we have seen efforts by various states to link the GATT and WTO to security and non-security issues with varying success based on specific issue areas. But in view of developing country opposition, particularly with respect to labor issues, and to environmental issues to a lesser degrees of WTO based linkages, as Vogel notes, the US and EU, have sought to engage in issue linkages in their negotiation of bilateral FTAs and through regional accords such as NAFTA.

We turn next to a consideration of linkage attempts in a variety of Asian minilateral regional accords. In contrast to the formal and legalistic nature of the WTO, many Asian minilateral arrangements are notable for their "soft law" character, non-binding agreements, and broad organizational domains. Several of these organizations were founded along the principles of the "ASEAN Way," which emphasizes consensus and consultation and condemns interference in the domestic affairs of sovereign states. Their cooperation on both economic and security issues tends to be somewhat amorphous, which makes the process of "linkage" more ambiguous. Consequently, we often fail to identify within these groupings the same types of linkages that we observe in formal bilateral trade agreements or even within the WTO. However, traditional security considerations played a driving role in the formation of many of these groupings, and some have also taken up a non-traditional security agenda to a limited extent.

Beginning at the Asia-Pacific level, APEC was created for explicitly economic purposes, prompted primarily by the economic threat posed by NAFTA and the European Union. As John Ravenhill points out in his chapter, for many years, APEC avoided any link between the organization's economic agenda and traditional security. Proposals by Australian and American leaders to address traditional security in APEC were met with resistance by Asian states, although some contentious issues such as the North Korean nuclear program and the East Timor crisis were discussed along the sidelines of various APEC summits. This changed dramatically in 2001, however, when the US took the radical step of linking counterterrorism to the APEC economic agenda in the aftermath of the September 
11 terrorist attacks. APEC issued its first formal proclamation on traditional security issues at its summit in October of that year. The US claimed that terrorism posed a clear threat to economic growth due both to the economic costs of the terrorist attacks and to the costs to government and businesses of attempting to reduce their vulnerability to such attacks. Although these arguments may have resonated somewhat with decisionmakers in APEC economies initially, they were increasingly perceived as a tactical linkage and accepted largely due to American power and US dominance over the APEC agenda. As a result, this presented an unstable linkage, and while the organization initially embarked upon a number of counterterrorism initiatives, disquiet on the part of APEC states eventually led to the issue being completely dropped from the APEC agenda by 2008 .

In addition to avoiding linkages to traditional security, APEC also never originally intended to address non-traditional security issues. However, as Ravenhill argues, economics and security are often difficult to completely disentangle, and one non-traditional security issue-energy security-was present on the APEC agenda from the very beginning. This inclusion reflected Japan's promotion of the concept of "comprehensive security," which emphasized raw materials and energy supply as essential to national security. Thus, it could be argued that at the organization's inception, Japan made a successful substantive linkage between APEC's economic agenda and energy. This connection made sense for highly energy import-dependent Asian economies as well as for energy exporters in the region. Energy issues remain a core part of APEC's working group activity to the present, and over time, the organization has also addressed other non-traditional security issues in response to regional events, increasing NGO pressure, and the need to maintain APEC's relevance as member economies increasingly turned their attention toward other regional and bilateral arrangements. For example, APEC devoted some attention to pandemic disease prevention after outbreaks of SARS and avian flu in the region. Proponents loosely linked the issue to trade, arguing that such pandemics threatened to disrupt regional commerce. Food security has also recently appeared on the APEC agenda. However, there have been no concrete ties between economic liberalization targets (themselves nonbinding) and these non-traditional security issues, and progress on this front should not be overstated. APEC has generally avoided linkages to contentious non-traditional security issues such as labor rights and migration, which might prompt unwanted interference in the domestic social and political policies of member economies.

In Chap. 4, Jonathan Chow describes the development of ASEAN, the region's oldest minilateral organization, created in 1967. In the case of ASEAN, traditional security clearly played the primary role in driving trade agreements during the Cold War period; as Chow argues, this early stage of economic cooperation was motivated by the need to maintain state sovereignty and autonomy as a matter of substantive linkage. This shifted in the 1990s as the end of the Cold War, the resolution of the Cambodian crisis, and the onset of the 1997 Asian Financial Crisis stimulated a new round of institutional development driven by economic factors. 
During this period of growing economic integration, ASEAN states became relatively more concerned with human security issues, as illustrated by the announcement of an envisioned "ASEAN Community" in 2003. However, ASEAN countries not only failed to link economic integration with human security, they purposefully delinked the two spheres. This separation was facilitated by ASEAN's underlying organizational structure, which emphasizes procedural norms of elite consensus, and by states' insistence that trade should not be used to extract non-trade concessions. In contrast to the debates about environment and labor that took place at the multilateral and bilateral levels, ASEAN states appeared to agree that intraregional trade should be insulated from these issues. ASEAN states considered the promotion of human security to be contrary to the notion of economic development, simply "protectionism by other means." American efforts to connect trade agreements to environmental, labor, and human rights standards were perceived as tactical maneuvers by ASEAN, which led to limited cooperation and the creation of an unstable issue linkage.

Since the 1997 Asian Financial Crisis, new developments in the region have led to fledgling mechanisms for environmental and human rights cooperation within ASEAN. Transboundary haze problems led to the 1997 Regional Haze Action Plan; however, the plan remains vague, has no sanctions for non-compliance, and has not been ratified by Indonesia, a key player. The development of democracy in Indonesia, increased concern about human rights within Malaysia, and Myanmar's human rights violations led to an increased appreciation of the relationship between human rights and ASEAN's institutional credibility. The ASEAN SocioCultural Community and the ASEAN Intergovernmental Commission on Human Rights represent two new but weak mechanisms in this area. Despite these nascent moves, however, there are still no binding linkages between trade and human security in ASEAN.

Many of the same dynamics can be seen in the "ASEAN Plus X" trade arrangements: ASEAN+1, ASEAN+3, and ASEAN+6/8 (more commonly known as the East Asia Summit). Min Gyo Koo's analysis in Chap. 5 focuses primarily on the linkage between economics and security in US foreign policy toward Asia, and the ways that the changes in the US approach catalyzed the development of the ASEAN Plus X groupings. During the Cold War, traditional security considerations were clearly linked to US economic policy in the region; in return for their bilateral security alliances with the US, East Asian partners received access to the US market and were encouraged to participate in multilateral forums such as the GATT and the UN which were supported by American hegemony. However, Koo argues that the end of the Cold War led the US to de-securitize its foreign policy, delinking security considerations from its economic policy. This resulted in a shift toward the US putting greater pressure on its East Asian allies, a change which became particularly evident in the aftermath of the Asian Financial Crisis when the US chose to push its longstanding economic partners to make neoliberal economic reforms instead of taking the softer approach that might have been dictated by security considerations. 
Koo argues that the desecuritization of US economic policy as showcased by the Asian Financial Crisis served as a wake-up call for East Asian countries, prompting them to seriously consider linking economic ties to security cooperation at the regional level. ASEAN +3, the ASEAN+1 dialogues, and the East Asia Summit were all motivated in part by disillusionment with the US and the perceived need for alternative arrangements. ASEAN+3 was formed as a direct response to the crisis, an alternative way for countries to create financial safety nets and explore increased market integration. The ASEAN+1 dialogues complemented the ASEAN+3 process, allowing ASEAN to pursue a more focused agenda with each of its Northeast Asian partners individually. Finally, the East Asia Summit was envisioned as a vehicle toward the formation of an eventual "East Asian community." These new groupings were not conceived in isolation; member states declared their intention to pursue "nested linkages" between ASEAN Plus X groupings and existing institutions, such as ASEAN, the UN, and others. However, as the institutional domains of these nascent groupings have broadened and blurred over time, it is unclear how successful their nesting within these other institutions or even amongst themselves will be.

In terms of underlying organizational structure, the ASEAN Plus $\mathrm{X}$ groupings are the most amorphous of Asia's would-be minilateral trade arrangements; however, connections between security and trade are still evident. While formal trade agreements have been proposed amongst essentially all of these "Plus X" configurations of countries, the ASEAN-China Free Trade Area (ACFTA) arranged under the ASEAN+China framework is the only formal agreement that has been concluded to date. ASEAN and China also signed a Joint Declaration on Cooperation in the Field of Non-traditional Security Issues alongside the ACFTA declaration, suggesting that China has attempted to link non-traditional security cooperation to economics as a means of reassuring ASEAN about its rise. ${ }^{5}$ However, despite the lack of concrete progress in other ASEAN $+\mathrm{X}$ groupings, the proliferation of proposals for trade agreements within these arrangements and the heated debates about what states should be included and excluded are evidence of the importance of traditional security considerations in driving the formation of trade agreements. Each ASEAN Plus X grouping might be seen as a different vision of the future of the Asian region, and major players such as China, Japan, and the US have an incentive to promote the institutions which best suit their interests. As Koo argues, East Asian countries often see these potential trade agreements as ways to pursue broader foreign policy and strategic objectives rather than purely economic goals. Since the Asian region lacks a single pacesetter, different countries use these ASEAN Plus X organizations as vehicles to share and compete for regional leadership.

The institutional agenda for these organizations has broadened over time, with various countries attempting to introduce non-traditional security issues such as energy cooperation and disaster relief onto the agenda of these organizations.

5 See also Arase (2010). 
The introduction of some of these issues might be interpreted as attempts to make tactical linkages between economic cooperation and non-traditional security. However, given the informal and incremental nature of cooperation within these forums, this trend is more often interpreted as an attempt to find some kind of actionable and noncontroversial agenda, a purpose for which non-traditional security issues are well suited. Even so, it is true that the ASEAN Plus X groupings have managed to have a small but positive impact on a variety of non-traditional security issues, even if that impact is peripheral to their stated institutional goals.

Koo argues that the US began to shift again toward a policy of securitizing economic policy toward Asia after the 9/11 terrorist attacks and that this shift has begun to complicate the environment in which the ASEAN Plus X groupings operate. Bilaterally, the US began to pursue FTAs with Malaysia, Thailand, Singapore, the Philippines, and South Korea, as well as with ASEAN as a whole. On a minilateral basis, the US sought to revitalize APEC, first through the proposal for a Free Trade Area of the Asia-Pacific (FTAAP) in 2006 and more recently through its promotion of the Trans-Pacific Partnership (TPP). US promotion of TPP is often considered to be in opposition to Chinese promotion of a trade agreement under the auspices of ASEAN+3; although TPP negotiations are far more advanced than those in ASEAN+3, this juxtaposition illustrates the tension between these competing arrangements. American resecuritization of economic policy is further illustrated by the US shift in position with regard to the East Asia Summit; while the US originally refrained from seeking membership in the EAS, it formally requested to join the grouping in 2010.

Turning to Central Asia, in Chap. 6, Ming Wan discusses the Shanghai Cooperation Organization, an organization in which China seems to be driving linkages between traditional security and economics. Like ASEAN, the SCO is an organization whose formation was motivated entirely by security concerns, primarily regarding reducing arms, building military trust, and bolstering member states' internal security through combating the "three isms" (terrorism, separatism, and extremism). The organization's formation also reflected mutual concern over US involvement in the region, and its members see the SCO as a hedge against Western expansion in the region. Over time, the SCO has moved to add economics to its agenda. This linkage between economics and security has been primarily driven by China, which, in addition to promoting a market for its goods, also wishes to ensure a peaceful environment for its expansion. While observers often note that much of China's economic cooperation with Central Asian states has taken place not through SCO channels but instead bilaterally, Wan points out that China took a significant step in advancing SCO-based economic cooperation in 2009 with the creation of a $\$ 10$ billion credit fund for member states. Economic initiatives serve as an incentive for cooperation within the SCO, which in turn bolsters the grouping's security agenda. While Russia has exhibited some wariness about Chinese intentions, the relatively small Central Asian states have responded positively to China's linkage strategy, viewing the SCO as serving their external and internal security goals as well as their desire for economic modernization. 
Given that SCO member states are not liberal democracies, it is not surprising that non-traditional security issues such as labor, environment, and human rights have not appeared on the organization's agenda. Wan suggests that the SCO has actually worsened the non-traditional security environment by supporting its members' efforts to bolster sovereignty and quell domestic dissent, for example. However, energy security is one non-traditional security issue that has been an important element in the organization's formation and its subsequent agenda. China needs the natural gas and petroleum of Russia and Central Asia to support its expansion, and these states in turn welcome China's economic resources. As with economic cooperation, much energy cooperation has taken place bilaterally instead of through the SCO; however, given the makeup of this institution, it is seems undeniable that energy security is linked to the economic considerations and negotiations of SCO member states.

We next turn to a consideration of bilateral FTAs, which are divided into four case study chapters. The first two focus on Asian accords, with Seungjoo Lee considering security factors and Atsushi Yamada concentrating on non-traditional security issues in their analysis of linkage politics. Vinod Aggarwal then considers US efforts to tie both security and non-traditional security issues to trade. Finally, Anders Ahnlid examines traditional and non-traditional security from an EU perspective.

We begin by examining traditional security linkage efforts by various Asian countries. In Chap. 7, Lee focuses on four countries in the region: China, Japan, Singapore, and South Korea. Drawing on John Ravenhill's work, (Ravenhill 2010) he argues that for the most part, Asian bilateral accords have been heavily influenced by security considerations, as evidenced by the many FTAs signed by big countries with smaller ones, their limited coverage, and the frequent absence of any significant business lobbying. He finds an important distinction between the strategies of bigger versus smaller powers, however. The former are focused on balancing strategies to counter each other's moves, while the latter are more concerned with enhancing their security-often by concluding accords with states outside the Asian region (such as the EU and US).

Lee's analysis of China's FTA strategy suggests that compared to other states, because of domestic policymaking centralization, China is able to systematically pursue clear foreign and security goals. In particular, the dominance of the Ministry of Foreign Affairs means that China could provide unilateral concessions to entice other countries to sign accords. In terms of strategy, China's efforts include allaying concerns about its rapid rise by engaging economically more deeply with ASEAN countries through the China-ASEAN FTA, which it proposed in 2000. Given that China entered the WTO as a developing country, it was also able to pursue FTAs and exclude politically sensitive economic sectors without being concerned about the "substantially all trade" requirement of Article 24 of the GATT when countries negotiate FTAs.

In contrast to China, Japan faces more constraints in its efforts to pursue security linkages in its FTAs. Responding to China's dramatic turn to concluding FTAs, particularly with the "ASEAN surprise," Japan sought to formalize FTAs 
of its own to go beyond its well-entrenched corporate based networks in the region. But as it sought to pursue security goals to respond to China's ASEAN initiative, it faced domestic pressures at home from protectionist groups who sought to block or delay negotiations. Moreover, its fragmented policymaking structure further impeded efforts to move forward. Faced with this challenge, the Koizumi government took direct action to support FTAs and pressed forward not only with Japan's accords with ASEAN but also initiated negotiations with Australia to balance against China's efforts. Still, it only recently concluded its 13th round of negotiations with Australia in December 2011, so domestic constraints on securing an FTA still remain despite the security context.

Turning to a smaller state, Lee emphasizes that security considerations are paramount in the case of Singapore. By focusing in particular on service sector liberalization (its tariffs are near zero in manufactured goods), Singapore attempted to entice as many countries as possible to sign FTAs with it. Moreover, it went well beyond East Asia, focusing on the US and more recently on the EU. In the former case, US goals of ensuring a presence in East Asia and countering China fit well with Singapore's efforts to enhance security linkages through an FTA.

Finally, Lee provides an in-depth analysis of the Korea-US FTA, emphasizing the link between trade and security. The importance of security can be seen in the willingness of Korean decisionmakers to confront protectionist groups, including filmmakers, auto, and agricultural interests, among others, by opening up these markets to meet US demands. As Lee notes, both trade and foreign ministers explicitly tied the FTA to security in the hope of bolstering diplomatic and security relations. At the same time, the FTA was also premised on the need for South Korea to enhance its security by becoming successful as a regional economic hub in East Asia.

Turning now to the use of non-traditional security linkages in Asian agreements, based on the Asia Regional Integration Center's database of Asian FTAs, Atsushi Yamada finds that non-traditional security linkages are a rarity. For example, with respect to labor, only one intra-Asian agreement (the Japan-Philippines EPA) has a provision dealing with workers and that too only in one article. By contrast, as he notes, the KORUS agreement has a whole chapter devoted to labor issues. Similarly, although some intra-Asian agreements mention the environment, the clauses are quite vague, in marked contrast again to KORUS. The one issue area that appears to be important, particularly in the case of Japan's accords, is the question of the mobility of workers. Why is there a lack of linkages to nontraditional security, besides worker mobility? Yamada focuses on the lack of domestic institutions that might allow lobbying by activists on these issues, as well as the authoritarian nature of many Asian countries, who do not want other states interfering in their domestic affairs.

Yamada provides an insightful case study of Japan's 2008 EPA with the Philippines (JPEPA), examining the linkage politics involved in Japan's agreement to accept 400 nurses and 600 caregivers. As he notes, this issue became controversial within Japan domestically. Domestic Japanese associations of nurses and 
caregivers viewed the Philippines' demand that its workers be admitted as a potential threat to their wages and job prospects. But the Japanese trade association Keidanren had strong interests in improved access to the Filipino market. The end result was a decision to accept both caregivers and nurses, but the issue of how their working conditions in Japan became controversial in the Philippines, leading environmental activists to join the fray and protest against their perceived threat to the environment that might arise as the result of Japanese exports of toxic wastes to the Philippines. In the end, the agreement passed. But given Japanese examination requirements which were very stringent and which made it difficult for Filipino nurses and caregivers to pass the qualification exams, Yamada argues that the linkage was inadequately thought through, resulting in an unstable issue linkage that has not been satisfactory to either the governments or the workers involved.

In Chap. 9, Vinod Aggarwal examines US policymaking on FTAs, focusing on both security and non-traditional security linkages. Given that the bulk of US FTAs were negotiated in the 2000s, he begins with providing a context for these accords by examining linkage politics prior to the US turn to bilateral FTAs. As he notes, consistent with Vogel's chapter discussed above, the US has long viewed trade politics as intimately linked to security. Whether in the GATT or the negotiation of sectorally-based bilateral restraints such as in textiles and apparel, security considerations have often been explicitly connected to trade.

In the late 1940s and early 1950s, free trade was seen as a means to bolster allies, both in Asia and in Europe. In the 1950s, the US helped Japan enter the GATT; about the same time, it ensured that the European Coal and Steel Community would not be ruled illegal by the GATT in light of its concerns of bolstering Europe to forestall encroachment by the Soviet Union. Still, in the early 1970s, the US was also willing to engage in tactical security linkages, pushing the Japanese to restrict their textile exports in the face of strong domestic lobbying by invoking the "Trading with the Enemy Act."

The first FTA that the US concluded, the one with Israel in 1985, had significant security overtones. The Reagan administration viewed the FTA as an opportunity to supplement its economic aid to Israel by giving it privileged access to the US market in the face of Congressional concern about the size of the aid package. Subsequent FTAs, first with Canada and then with Mexico, were not directly connected to military security. But in the case of negotiations over NAFTA, Mexico's political stability was a significant consideration in the wake of the domestic unrest during the $1980 \mathrm{~s}$ debt crisis.

The decision to purse NAFTA proved decisive in increasing the activism of environmental and labor groups, both in the US and Canada. Prior to this accord, the US had pushed for labor clauses when it renewed its unilateral preferences system for developing countries in 1984. But with NAFTA, the US government began to actively negotiate to link environmental and labor issues to trade in the face of growing domestic discontent. Activists' dissatisfaction on the environmental protection front was driven in part by the dolphin-tuna dispute settlement ruling in the GATT in 1991, which Vogel discusses. Critical of the GATT's 
decision to reject US efforts to impose a ban on tuna from Mexico, and joined by trade unions, they agitated for provisions to trade to environmental and labor regulation. In the end, President Bill Clinton's decision to push for side agreements with Mexico on labor and the environment as part of the process of ratifying NAFTA did little to satisfy activists on this score, and only increased the domestic politicization of these issues. As a result, trade linkages became highly contentious, leading the groups to push Cambodia to go along with labor standards in textile bilateral accords. The contentiousness of trade-labor linkages was most visible in the debacle in Seattle that blocked the start of a new round of trade negotiations in the WTO.

In 2000, the efforts to actively link trade to environmental and labor issues as well as to security concerns, took an important turn with the first US FTA of the new millennium with Jordan. With security considerations crucial, and domestic groups activated, Jordan agreed to include labor and environmental standards in the actual text of the FTA. The accord, signed in October 2000, included references to the ILO 1998 Declaration on Fundamental Principles and Right of Work, and also provisions noting that countries would not relax their environmental standards to foster trade.

The next important phase of linkage politics, both domestically and internationally, came about with the active American pursuit of FTAs in the 2000s. President Bush's effort to secure Trade Promotion Authority (TPA) was facilitated by the linkage to the attacks of $9 / 11$, and the bill became law in 2002. Although trade was linked to the environment and labor, the provisions were weaker than in the Jordan agreement. With TPA in hand, the Bush administration negotiated a host of FTAs. Democrats viewed their success in the 2006 Congressional elections as an opportunity to more aggressively link these issues to trade. The outcome of intense negotiations was the 2007 New Trade Policy agreements, which became template for both pending and new FTAs. Links to the ILO on labor were strengthened and the agreement also called for direct ties to international environmental accords.

On the whole, in terms of recent US FTAs, in considering a variety of driving factors and linkage efforts, Aggarwal finds that security has tended to play a strong role in many FTAs, particularly with Morocco, Bahrain, and Oman, as well as to a lesser extent with, Singapore, Chile, and Australia. In terms of non-security factors, these have become particularly salient in the DR-CAFTA accord, as well as Peru, Colombia, and Panama. As we shall see, however, whereas security is a significant factor in US accords, and is implicitly linked in many FTAs, the US approach contrasts sharply with that of the EU, which has explicitly included security provisions in its FTAs.

Anders Ahnlid's analysis of the EU in Chap. 10 points to longstanding linkages between trade and both traditional and non-traditional security considerations, going back to the creation of the Economic Coal and Steel Community. Strong security linkages drove this accord, and later the externalization of a wide array of security concerns including democracy and human rights formed key linkages in the EU's enlargement policies. These concerns were made explicit with the 
so-called "Copenhagen Criteria" regarding the political and economic conditions for accession. In the EU's agreements with colonies of former EU members, the preferential arrangements that began with the so-called African, Caribbean, and Pacific countries (ACP) through the Yaoundé and then Lomé Conventions, evolved into the Cotonou Agreement. These latter accords contain explicit linkages on human rights, peace, and other non-traditional security concerns. Eventually, these accession and former colonial linkage ideas began to be applied to negotiations with other states as well.

Although the EU began to worry about economic competition to create FTAs in the 2000s, the extent to which linkages to other issues should be part of the negotiations was contested. Still, with the Lisbon Treaty's granting of greater powers to the Parliament, the Commission found itself pressured by interest groups and their Parliamentary supporters to continue the previous linkage policy to security, human rights and development. The security elements to be included covered the non-proliferation of nuclear weapons, trade in small arms, counterterrorism, and the International Criminal Court. Other political clauses span the gamut from human rights, democracy, and migration, to the rule of law. Moreover, these clauses had teeth: suspension of a trade agreement was possible in the case of non-compliance.

With respect to sustainable development linkages, the EU included labor rights and environmental issues. Target countries have often seen these as tactical linkage efforts, simply disguised protectionism intended to diminish their global competitiveness. Still, the EU has continued to insist on these clauses, with success in view of the temptation of states interested in market access.

Ahnlid explores linkage politics with respect to four groups of countries: prospective EU candidates; other neighbors; Cotonou countries; and more "distant" countries. Each has a distinctive set of linkage dynamics. The Copenhagen criteria, emphasizing a host of political issues, have generally been seen by target states such as Croatia as substantive linkages connected to accession. Even long-standing applicants such as Turkey have accepted the principle of adhering to the Copenhagen criteria, but with domestic politics in Turkey often generating debate over next steps.

In the case of other neighbors, the promise of association agreements with the EU have proved to be tempting enough to encourage them to move toward acceptance of such linkages, and it does not appear that this is simply only tactical on their part. Still, there have been cases where the EU has refused to sign agreements with states such as Ukraine over democratic concerns or suspended negotiations as in the case of Libya in view of the conflict in the country. In the case of Arab countries, and the Gulf Cooperation Council, in light of the Arab Spring in 2011, the perception of political and other linkages is clearly in transition.

For the ACP countries, the decision to agree to various political and development clauses appears to stem from their weakness, in Ahnlid's analysis. As he notes, their desire to secure access to the EU market has made them willing to accept clauses that they don't particularly support. For its part, the EU has been willing to wield the stick, invoking a suspension clause in over twenty cases since 1995. 
Finally, with respect to more distant countries, the EU has sought economic gains rather than progress toward its security goals. Agreements with South Africa, Mexico, Chile, and now more recently South Korea reflect these interests. In many cases, despite the EU's primarily economic objectives, political clauses have led to delays and disputes. In the Korea case, for example, there was a compromise on the timetable for possible suspension in cases of non-compliance, and in the end, agreements on a host of labor and environmental provisions. The Koreans, it would appear, increasingly view these connections as substantive links in light of their own green initiatives. The most interesting analytical case concerns India. Here, the political clauses have proven to be a stumbling block, and India has not been willing to go along with clauses that the EU has included in every FTA it has negotiated. But in view of EU business interests' concern about securing access to the Indian market, the EU now finds itself caught between its economic objectives and the precedent it has set of always including both political and social clauses in its FTAs. Thus, this case poses the key question of whether the EU would be willing to alter its policies-when power is not as asymmetric or when there is no consensus on linkages to trade.

\subsection{Themes and the Future of Linkages in the Asia-Pacific}

In this section, we attempt to outline some general themes that emerge from the chapters in this volume in order to characterize trade-security linkages as they are used by the US, Europe, and various Asian countries. We begin with the issue of security (both traditional and non-traditional) as a driver of trade arrangements before turning to a discussion of how the characteristics of a trade arrangementin terms of number of participants, geographical scope, and organizational structure-act as intervening variables in the linkage process. We then comment on patterns in types of trade-security linkages (tactical versus substantive) and on the effects of trade agreements on the security environment. We conclude with some of our expectations about the future of linkage formation, particularly in the AsiaPacific.

\subsubsection{Traditional and Non-Traditional Security as Drivers of Trade Agreements}

Looking at the cases discussed in this volume, it is clear that traditional security continues to play a key role in the formation of trade arrangements, particularly at the bilateral and minilateral levels. Asian bilateral trade agreements have been heavily influenced by security considerations, with larger powers attempting to balance against one another and smaller powers trying to enhance their security by 
concluding bilateral agreements extra-regional powers such as the EU and the US. ASEAN and the SCO both started out as organizations explicitly oriented toward dealing with traditional security issues, with key players only subsequently making linkages to economic issues. According to Min Gyo Koo, the formation of ASEAN+3 was partly a reaction to the perceived "desecuritization" of US foreign economic policy in the aftermath of the Asian Financial Crisis. The recurring debate about what countries should most appropriately be included in the East Asian Summit illustrates the stake that major powers have in defining the "Asian" region in a way that best suits their strategic security interests. The WTO too was originally formed with Cold War considerations in mind.

In contrast, non-traditional security has played a relatively minor role in driving the formation of Asian trade arrangements. While the US and the EU have displayed concern over labor rights, human rights, and the environment, Asian bilateral agreements neglect non-traditional security issues almost completely. While Japan's recent EPAs with the Philippines and Indonesia represent a rare attempt to incorporate labor into Asian bilateral trade agreements, these EPAs continue to face many challenges, as outlined by Yamada in this volume. ${ }^{6}$ The most common linkage between non-traditional security and economics in the Asian context involves energy security, as seen in APEC and the SCO. Given the concern over resource scarcity shared by a number of Asian states, this is a logical and relatively non-controversial linkage. However, energy security has not played a central role in driving trade agreements, nor has it been bindingly linked to trade; instead, it has been a byproduct or subordinate component of economic cooperation.

\subsubsection{The Influence of Organizational Size, Structure, and Scope}

Linking trade and security becomes more difficult as the number of participants in a trade arrangement increases. We see the most concrete linkage activity at the bilateral level. When only two actors are involved, asymmetric distribution of power has the potential to play a large role in bringing an agreement to a close; it may also be easier for them to come to a consensus about shared values and concerns. The strategic and economic tradeoffs being made are relatively clear to the parties involved. At the minilateral and multilateral levels, linkages have reflected countries' concerns about the regional or international security environment and about balance of power. As the number of participants increases, however, it becomes more difficult to reach a consensus, and as a result, linkages have been most successful where asymmetry of power has allowed one country to dominate the agenda setting process. We see this with China in the case of the

\footnotetext{
6 The KORUS FTA is another notable exception, but as Yamada argues, the labor and environment provisions in KORUS reflect US concerns, not those of South Korea.
} 
SCO and the US in APEC post-9/11. In ASEAN, external economic and security threats have helped to bring member states together to some extent. With regard to other minilateral groupings-ASEAN+1, ASEAN+3, East Asia Summit, and APEC - power struggles between China, Japan, ASEAN, and the US have resulted in a number of overlapping organizations being pursued simultaneously as a hedging strategy, both in terms of economics and security. However, economics and security have rarely been linked in binding ways in these regional minilateral arrangements. Multilaterally, the GATT/WTO system was historically linked to the Cold War and the promotion of economic growth in Western capitalist countries, and security issues have also appeared in the context of membership issues. Linkages between economics and non-traditional security issues have been relatively rare in groupings of all sizes, but again, we see linkages being made most frequently at the bilateral level, as exhibited by labor and environmental provisions in FTAs concluded by the EU and the US. In contrast, it has been more difficult to link trade to human security issues at the regional level and in the WTO, where, despite attempts, there have been no binding linkages between trade and environmental or labor standards.

Underlying organizational structure plays an important role in defining the way that linkages play out in each of these agreements. Where formal agreements exist, as with bilateral FTAs and in the WTO, binding trade-security linkages become possible. However, the story is very different with regard to the Asian region's nascent multilateral groupings, whose amorphous structure and soft law orientation make specific tradeoffs or binding linkages practically impossible; it is difficult to link an economic agenda to security concerns when goals and activity on both fronts are highly ambiguous. Instead, as mentioned above, trade and security linkages take the form of debates over appropriate membership structure and over what organization should be seen as the premier vehicle for regional cooperation, which reflects the divergent preferences of Japan, China, ASEAN, and the US regarding what the Asian region should look like. Specifically, China would prefer that regionalism be driven through $\mathrm{ASEAN}+3$, a forum in which it can dominate, while Japan would prefer to balance against China by bringing in countries such as the US, India, and Australia. ASEAN too has an interest in maintaining its place in the "driver's seat" of regional cooperation, lest it be sidelined by the larger powers in the region. Interestingly, countries have attempted to include linkages to nontraditional security in these organizations, to increase their legitimacy through cooperation in noncontroversial fields such as disaster relief and disease prevention. However, again, these non-traditional security issues have not been bindingly linked to economic goals or targets.

With regard to the relationship between geographic scope and trade-security linkages, our findings are mixed; in general, security concerns seem to be more salient among geographically concentrated countries, but agreements involving the US are an exception to this pattern. In the case of the EU, security concerns play a larger role in bilateral trade agreements with more geographically proximate states, particularly potential EU members, while FTAs with more distant partners are driven more by economic gains. With the US, however, security considerations 
are an integral part of its trade strategy with countries both near and far due to its current status as the global superpower. American strategic interests played a key role in its FTAs with countries such as with Jordan, Israel, and Morocco, despite lack of geographic proximity. With regard to the Asian region, security concerns are generally more salient with regard to geographically concentrated countries. This is particularly obvious in groupings such as the SCO and ASEAN, but more broadly, the heated debates about membership in various regional minilateral groupings also reflect anxieties about security. However, again, the US is a notable exception to this pattern. Despite technically being an extra-regional power, the US plays a defining role in the security architecture of the Asian region, and as such, all agreements between the US and Asian countries involve security considerations to some extent.

\subsubsection{Linkage Dynamics}

Of the types of linkages outlined in our theoretical framework, tactical linkages appear frequently in the cases examined in this volume. Large powers such as the EU, the US, and sometimes China leverage asymmetrical power to set the agenda for negotiations and to link economic issues to their security goals. The US, for example, has used this strategy in fora at every level, from its bilateral trade agreements to its attempts to garner support for the war on terror in APEC and the WTO. In the minilateral context, this tactical linkage strategy has often resulted in unstable or failed linkages, as smaller countries have come to reject these linkages over time. The EU has been described by some as using a similar strategy of tactical linkages to promote its "interests and values," particularly in dealings with EU candidates. Although China is still establishing itself as a regional and global power, in some contexts such as the SCO or the ASEAN+China dialogue, it has been able to use economic cooperation as a means of ensuring a stable security environment and assuaging fears about its rise. Countries have sometimes attempted to tactically link economic cooperation with non-traditional security as well, mostly as a means of bolstering the legitimacy their minilateral grouping of choice and thereby increase their regional influence.

Attempts to substantively link economics and traditional security concerns have also been fairly common throughout the post-World War II period, but linkages between economics and human security have been seen much more rarely. The US and the EU are exceptions to this, as described by Aggarwal and Ahnlid in this volume. Responding to social pressure, the US began to make claims that trade, labor, and the environment are substantively linked in the 1990s, and the 2000 USJordan FTA was the first to explicitly include labor and environmental provisions in the text of the agreement. The EU has explicitly tried to promote peace, democracy, human rights, and sustainable development through its trade policy, both within the EU, as a condition for accession, and in its agreements with third countries. Critics might argue that both the EU and US have really been disguising 
tactical linkages as substantive ones. However, these types of substantive linkages between trade and human security are rarely attempted by Asian countries and even more rarely believed by their negotiating partners. This is unsurprising, given the lack of trust and tension between many countries in the Asian region. While consensus is sometimes achievable on the traditional security front, Asian countries remain highly skeptical of the argument that non-traditional security issues such as labor rights, human rights, and the environment are substantively linked to economics, instead seeing these linkage attempts as simply protectionism by other means. Indeed, as Chow argues, ASEAN has even taken active steps to delink economics from non-traditional security to the greatest extent possible, a move that reflects member countries' belief that such non-traditional security is actually inimical to economic and traditional security goals.

\subsubsection{The Effects of Trade Arrangements on the Security Environment}

Given the relative youth of many of these trade arrangements and measurement difficulties in assessing their impact, it is difficult to make concrete conclusions about how these trade arrangements have impacted the Asian regional security environment. However, we can make some general statements based on the findings in the preceding chapters. First, trade arrangements have undeniably been used by countries as tools with which to bolster existing security alliances and recruit new partners, as seen in cases as diverse as the KORUS FTA and the SCO, and to address balance of power considerations. Second, the proliferation of minilateral trade arrangements in particular has greatly increased the interaction between Asian countries and created a number of channels and opportunities for communication that have sometimes been used to deal indirectly with traditional security issues. Third, and perhaps unexpectedly, some tangible gains have been realized in the arena of non-traditional security. While Asian minilateral economic organizations are often criticized for their lack of concrete action, the flurry of nontraditional security initiatives seen over the last decade has resulted in at least limited cooperation in areas such as disaster relief, disease prevention, control of environmental problems, and the like. Although these activities may be peripheral to the stated missions of these organizations and not concretely linked to economic issues, this type of non-traditional cooperation would arguably be less common if not for these minilateral groupings.

\subsubsection{Future Prospects}

As our review of the empirical work has found, the US and EU are the most active in the use of linkages, both traditional and nontraditional, in bilateral, minilateral, 
and multilateral arrangement settings. By contrast, Asian countries have emphasized traditional security concerns at the bilateral and minilateral level in particular in their own negotiations. Will this differential pattern continue in the future? Here, we must look to the domestic politics of linkage formation and agenda setting.

With respect to nontraditional security, it would appear that the US and the EU will continue to attempt to engage in such linkages, both for domestic reasons with strong activist groups who push for labor and environmental standards in particular. Moreover, it would appear that the EU Commission, with its longstanding efforts to include not only these types of provisions but democracy and human rights issues as well in its relations with prospective accession states as well as poorer countries, shows little sign of shifting away from their use. Up to this point, both the US and EU have to this point had considerable success in pressing other states to accept such linkages in bilateral negotiations, although it is difficult to ascertain whether they have done so for substantive or tactical reasons. As Ahnlid suggests, given the power asymmetry or similarity of interests of the EU with countries with which it has sought bilateral FTAs to this point, there is little reason to believe that the EU would not continue to make these efforts and succeed on the whole, particularly in light of increasing EU parliamentary constraints on the Commission. But success with large countries such as India where the EU meets resistance may well be a different story, and lead to quiet exceptions to its linkage efforts. For its part, in the bilateral FTAs now being pursued primarily through the TPP process, the US has clearly made non-traditional security linkages an integral part of the negotiations. But up to this point, the TPP process has also consisted of the US and a group of relatively smaller countries, so success on this score is hardly surprising. Here, as in the case of the EU, efforts to expand the TPP to larger, more recalcitrant countries will prove a challenge.

For Asian countries, non-traditional security linkages to trade do not appear to be a central concern, and are unlikely to become one. Although some nascent efforts have been made on this score in fora such as ASEAN, as we have seen, these have been relatively weak and not binding in any case. This pattern appears within the "ASEAN Plus X" groupings as well. With sharply differing views of many countries regarding human security issues, a strong norm of non-interference, a top-down decision-making process, and a relative paucity of strong interest groups able to successfully put these issues on the negotiating agenda, we see no reason to believe that the use of such linkages will become the norm in Asia anytime soon.

With respect to traditional security concerns, most countries have been eager to enhance their perceived security through the use of linkages to trade. This pattern is common to the accords at the bilateral and minilateral level by the EU, US, and Asian countries. But having said this, the more explicit efforts of the EU to attempt to alter other countries' policies (on WMD or small arms, for example) has been met with some resistance. Thus, even if they are included in trade accords, one might expect the resulting agreements to have little constraining value-except with very weak countries that the EU can threaten or 
sanction with ease. There is little reason to believe that this pattern will change. With Asian countries as the most active participants in negotiating FTAs, security linkages to trade are likely to be a common phenomenon.

Looking to the future, then, linkages between trade and both traditional and non-traditional security will continue. In Asia in particular, the elite-driven process means that policymakers will view any agreements with other countries-even if technically only about trade-as an opportunity to enhance their alliances and alter the broader security context through confidence-building. The EU and US are likely to follow this pattern as well. But with respect to the use of non-traditional security linkages, as we continue to see an increasing shift of power toward the emerging countries, the limitations on the efforts of the EU and the US on these issues will become increasingly apparent.

\section{References}

Aggarwal, Vinod K. 1998. Institutional designs for a complex world: Bargaining, linkages, and nesting. Ithaca: Cornell University Press.

Aggarwal, Vinod. 2001. Economics: International trade. In Managing global issues: lessons learned, ed. P.J. Simmons and Chantal de Jonge Oudraat, 234-280. Washington: The Carnegie Endowment for International Peace.

Arase, David. 2010. Non-traditional security in China-ASEAN cooperation: The institutionalization of regional security cooperation and the evolution of East Asian regionalism. Asian Survey 50(4): 808-833.

Haas, Ernst. 1980. Why collaborate? Issue-linkage and international regimes. World Politics 32(3): 357-405.

Hafner-Burton, Emilie. 2005. Trading human rights: How preferential trade agreements influence government repression. International Organization 59(3): 593-629.

Higgott, Richard. 2004. After neoliberal globalization: The "securitization" of US Foreign Economic Policy in East Asia. Critical Asian Studies 36(3): 425-444.

Oye, Kenneth. 1992. Economic discrimination and political exchange. Princeton: Princeton University Press.

Pekkanen, Saadia. Forthcoming. Asian designs: Interests, Identities, and States in External Institutions.

Ravenhill, John. 2010. The 'new East Asian regionalism': A political domino effect. Review of International Political Economy 17(2): 178-208.

Vogel, David. 1995. Trading up: Consumer and environmental regulation in a global economy. Cambridge: Harvard University Press. 